\title{
Mapping foreign nationals in Spain: an exploratory approach at local level
}

\author{
Sébastien Oliveau², Quentin Larue ${ }^{2}$, Yoann Doignon ${ }^{1,2^{*}}$ (D) and Isabelle Blöss-Widmer ${ }^{1}$
}

\author{
* Correspondence: yoann.doignon@ \\ univ-amu.fr \\ ${ }^{1}$ Aix Marseille Univ, CNRS, LAMES, \\ UMR 7305, Aix-en-Provence, France \\ ${ }^{2}$ Aix Marseille Univ, Université Côte \\ d'Azur, Avignon Université, CNRS \\ ESPACE, UMR 7300, Avignon, France
}

\begin{abstract}
Spain, which has long been a country of emigration, has become, within a few years, one of the European countries which welcomes the most foreign nationals onto its territory. These foreign nationals constitute a boon from a demographic point of view, limiting the depopulation of the territory induced by its accelerated ageing. Nevertheless, the establishment of foreign nationals is not a phenomenon that is equally distributed over the area. Indeed, foreign nationals are not equally located over Spanish territory. The spatial inequalities in their distribution merit specific attention, especially as they show significant differences according to countries of origin. Relying on data from municipal population registers (Padrón), this article offers a fine-scale, detailed exploration of the distribution of foreign nationals in Spain, to highlight the logic of differentiated occupation of Spanish space. The results show that certain nationalities occupy the territories without much sharing (Romanians and Bulgarians in rural areas for example), while others cohabit with different nationalities (Germans and English in recreational areas). Finally, certain nationalities (Moroccans in particular) are present in very specific locations, where there is an alternation of shared territories and exclusive occupation.
\end{abstract}

Keywords: Migrations, Foreign nationals, Population diversity and composition, Spatial analysis, Local indicators of Spatial Association

\section{Introduction}

The adhesion to the European Union has changed the migration profile of Spain. From a country of emigration, Spain has become a country of immigration. Since then, this trend tends to reinforce. Spain has been a major host country for foreign populations since the end of the twentieth century. Until 2012, the number of foreigners is increasing very strongly. Spain has one of the highest immigration rates in the world. In the period 2009-2012, foreigners account for more than $12 \%$ of the population. Even though their proportion and number have decreased due to the economic crisis, they still represent $10 \%$ of the total population. Moreover, geographical origin of immigrants is extremely varied: South America (with an obvious linguistic and historical link), North Africa (due to spatial proximity), and also from the European Union (for reasons of quality of life or jobs).

However, given the scale of immigration since the early 2000s, it is very surprising to note a lack of geographical studies on the spatial distribution of foreigners throughout Spain. However, the Spanish statistical institute provides the demographic data of the

(c) The Author(s). 2019 Open Access This article is distributed under the terms of the Creative Commons Attribution 4.0 International License (http://creativecommons.org/licenses/by/4.0/), which permits unrestricted use, distribution, and reproduction in any medium, provided you give appropriate credit to the original author(s) and the source, provide a link to the Creative Commons license, and indicate if changes were made. 
population register (Padrón) on foreigners at a very fine geographical level (municipios). In fact, studies on migration in Spain are generally concentrated either globally at a countrywide level or at the level of a region or a city. Studies exist at the provincial level for the whole country (Maza, Villaverde, and Hierro, 2013). In the same way, studies described immigration precisely at province scale (Bayona-i-Carrasco and Gil-Alonso, 2013) or inside the main cities (Martori, Madariaga, and Oller, 2016). However, no study deals with migration from both a detailed level of analysis (municipal level) and also covering the whole of the Spanish territory.

This article proposes to fill this gap in the literature by considering migrations in Spain from the angle of the spatial distribution of foreign nationals for the whole country, but at a detailed geographical level: the municipalities. From a geographical point of view, literature has long shown that migrants do not randomly distribute themselves over territories (Duncan, 1957). Migration routes are spatially structured, and the geographical origin of migrants does influence their destination. We can therefore reasonably assume that the distribution of foreign nationals over Spanish territory is not random. We should also be able to observe spatial concentrations and specific geography to each nationality. The approach of this article is therefore intentionally exploratory and descriptive. Indeed, we want to reveal the spatial structures of foreigners throughout Spain, which no study has shown so far.

After briefly recalling the history of migration in Spain, we will present the Spanish population registers (Padrón) that were used to conduct the analyses. We will then detail the methodologies used successively to explore the spatial distribution of foreign nationals. The results are finally explained and discussed. We remind that foreign nationals in Spain are numerous, and their location shows a very strong spatial organization that deserves to be highlighted.

\section{Spatial distribution of foreign nationals in Spain: a micro-level approach}

While Spain was a country of mass emigration during the twentieth century, the tide turned in the mid-1980s making it a country of destination, attracting more and more foreign nationals. We find a plurality of migration profiles (Maza et al., 2013) not only economic migrants from South American, African, and Eastern European countries, but also migrants from the Northern European countries who came to benefit, mainly for their retirement, from coastal climatic conditions and a relatively low cost of living (Rodriguez, Fernandez-Mayoralas, and Rojo, 2004).

Immigration to Spain has never been at zero, even if emigration used to be much higher. The death of Franco marked the return of some of the Spaniards who had moved to live elsewhere in Europe and South America. However, it was when Spain entered the European Union in 1986 and benefited from the related economic boom that the number of foreign nationals began to rise steadily. There were then about 300,000 foreign nationals on Spanish soil (Munoz-Pérez and Escribano, 1989). Ten years later, population registers revealed that their numbers had doubled. It was only at the beginning of the twenty-first century that the proportion of foreign nationals drastically increased (Cornelius, 2004). Between 2000 and 2008, the number of foreign nationals residing in Spain increased from 900,000 to over 5.5 million (Fig. 1). However, this phase of growth was interrupted in 2008, when the effects of the economic crisis started to hit home. Rising unemployment and falling GDP were the two most 


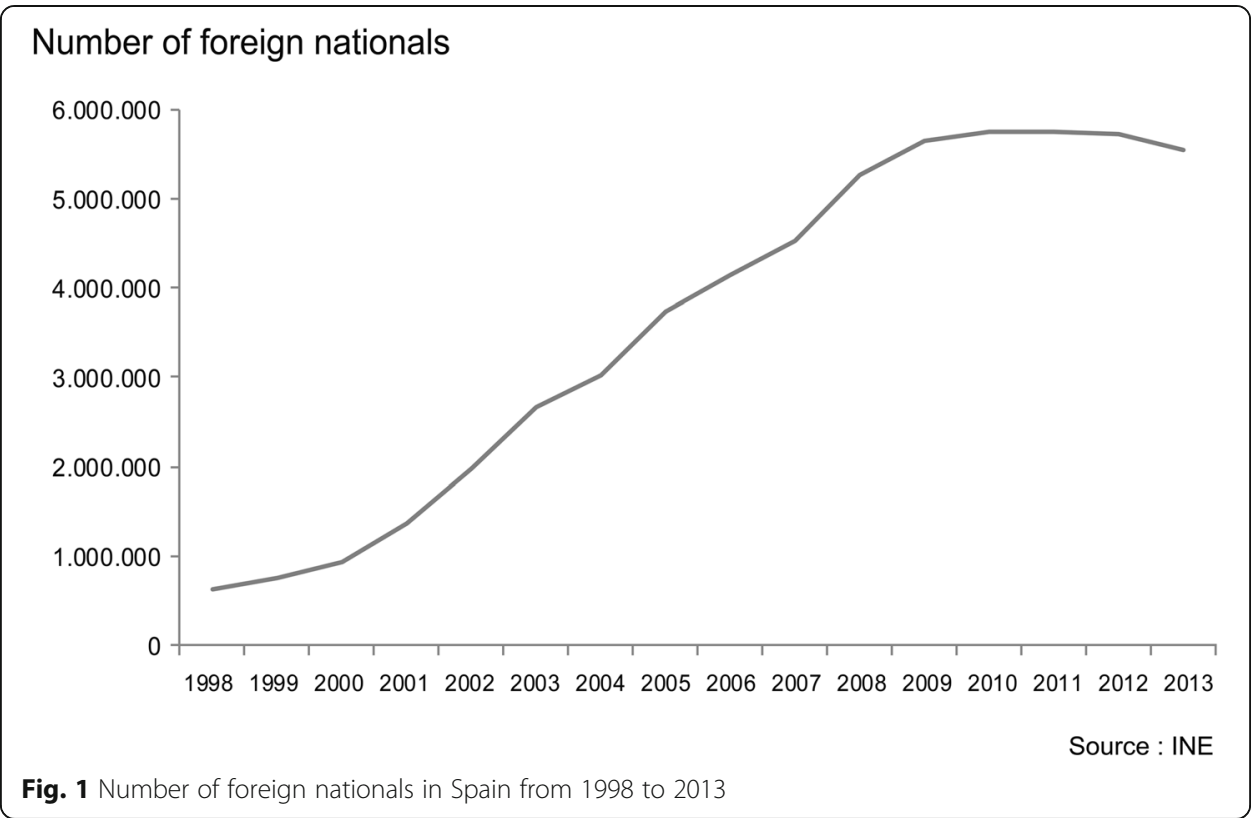

sensitive markers for the population (Domingo, Domingo, and Valverde, 2010). The foreign population level began to stagnate then declined starting from 2013. A double trend can explain this observation: foreign nationals are leaving in greater numbers (rising emigration) and arriving in fewer numbers (decline in immigration), as illustrated in Fig. 2. Net migration became negative in 2011 (Larramona, 2013), and population growth became negative from 2012 onwards. In 2013, Spain lost more than 200,000 inhabitants.

The aforementioned general trends concern Spain as a whole. Nevertheless, by adopting a subnational approach and a finer level of analysis, it is interesting to note that foreign nationals are not evenly distributed across the territory (Domingo et al., 2010; Maza et al., 2013). "The distribution of immigrants across the territory is obviously a geographical

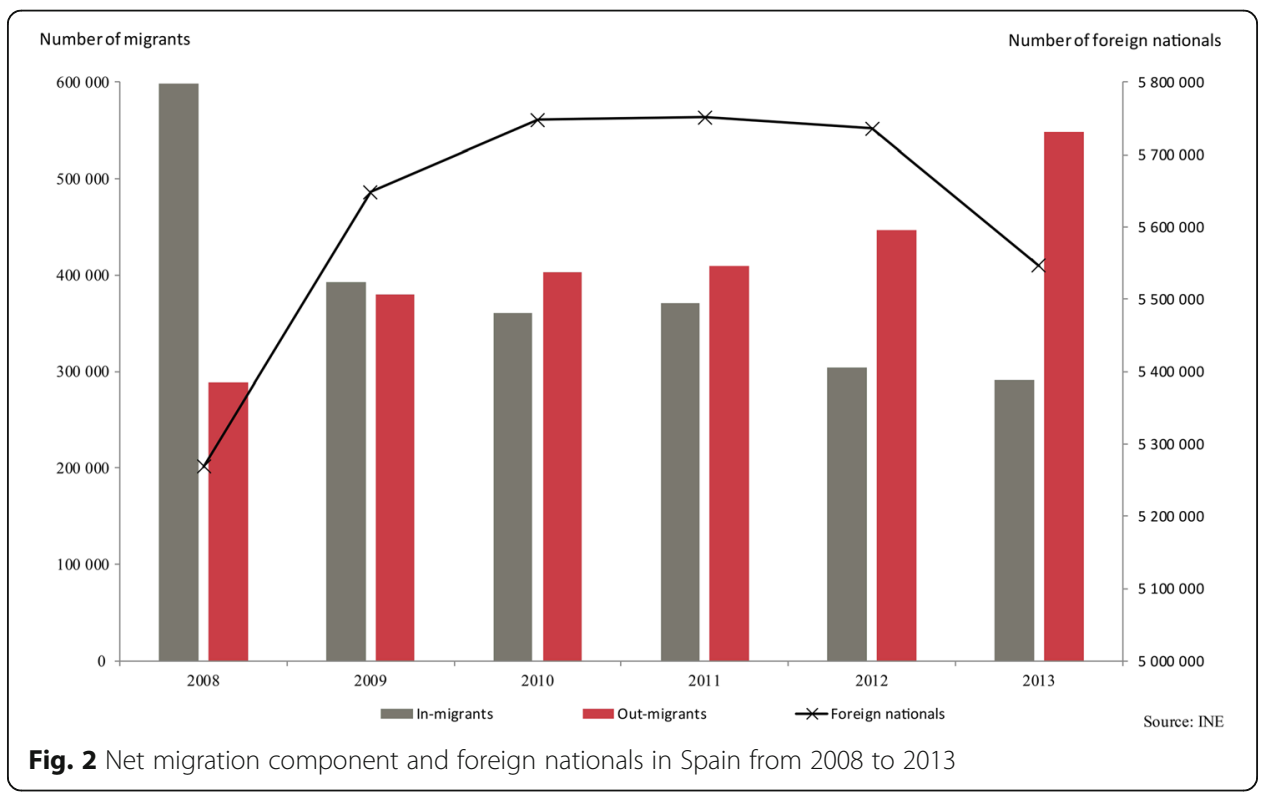


issue", as Pérez and Medina (2004) remind us. We highlight these remarks in particular by mapping the proportion of foreign nationals in the total population at the local municipality level (Map 1). With very few present in the western half of the country, they are far more numerous on the Mediterranean coast and in the Madrid urban area, representing in many places more than a quarter of the total population (Maza et al., 2013). Moreover, in Spain like in other countries, the distribution of foreign nationals differs according to their origin, revealing remarkable concentrations of some nationalities. It is therefore interesting to explore the distribution of foreign nationals and their increase on a fine scale by distinguishing their geographical origin, which the publications on the subject do not do, or do so only in the form of local monographs (Pérez and Medina, 2004; Bayona-i-Carrasco and Gil-Alonso, 2013; Martori et al., 2016).

The theoretical literature on the spatial clustering of migrants at the intra-urban scale dates back to the School of Chicago in the 1920s. It has since experienced many developments, including methodological. The segregation measures have been widely mobilized since the work of Massey and Denton (1988). Reardon and O'Sullivan (2004) rely on two specific dimensions of residential segregation: clustering and isolation. In this spirit, we will use Local Indicators of Spatial Association (LISA) (Anselin, 1995) to highlight clustering and Hierarchical Ascending Classifications (HAC) to show isolation.

\section{Data from the Padrón Continuo (continuous register)}

Measuring migration is a difficult statistical and demographic exercise. Statistics on immigration and emigration flows, where they exist, are generally unreliable. Indeed, they require costly administrative and supervisory bodies, which few states are capable of, or are prepared to implement. To measure the migration phenomenon, it is considered

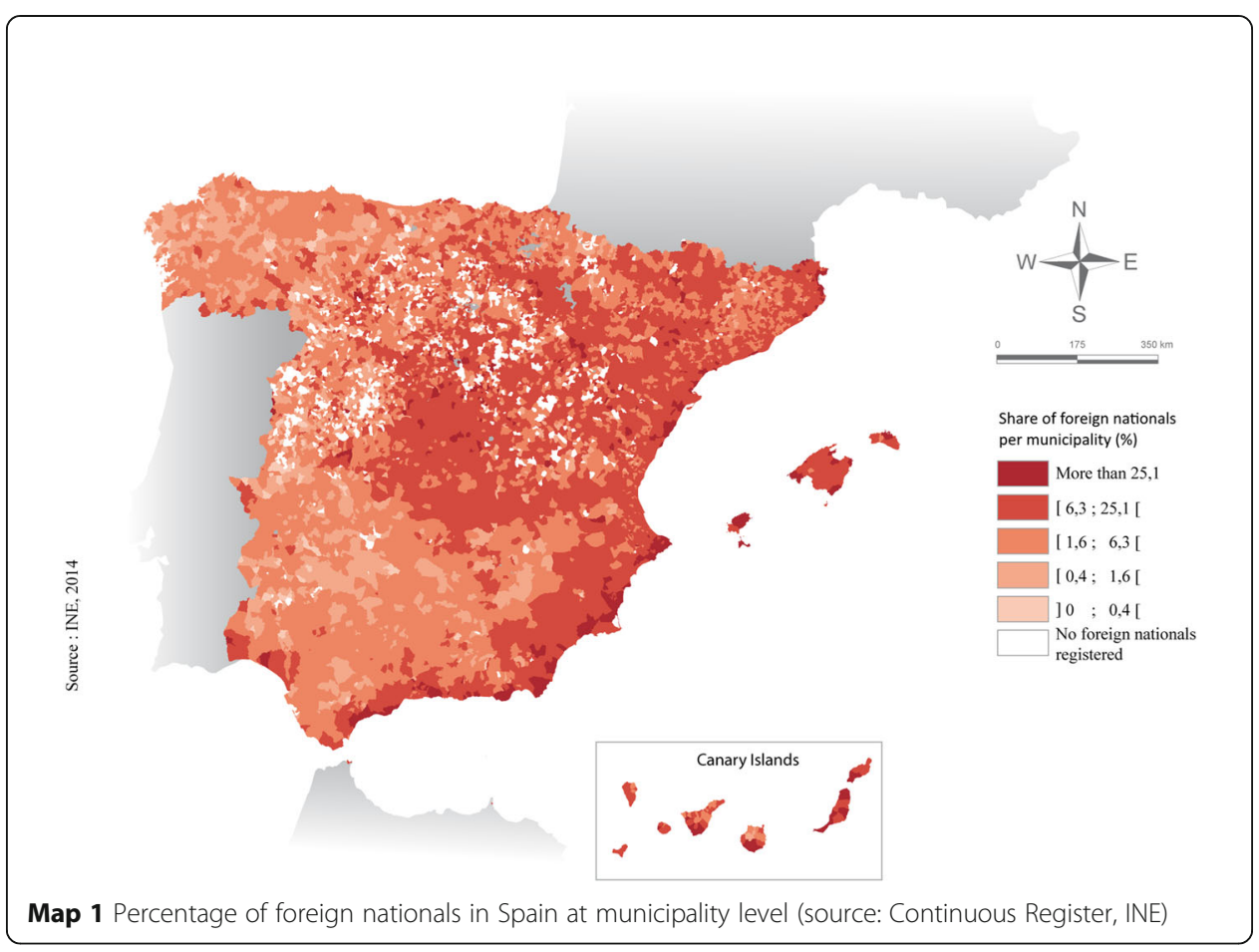


preferable in this context to work on stock statistics rather than flow statistics. For this purpose, population censuses are widely used, although they are still poorly adapted to this use because of the temporal spacing between the holding of two censuses. Spain organizes censuses at intervals of 10 years. ${ }^{1}$ This time window is far too large to measure migratory phenomena, which may also be somewhat cyclical. Moreover, the definition of migration may vary between one census to another, which complicates international comparisons and sometimes even national comparisons between two dates (Poulain, Perrin, and Singleton, 2006). Surveys remain an interesting alternative, but few of them take place on a regular basis and with consistent use of definitions. Finally, population registers, where they exist, offer an interesting solution since they record continuously (or at least annually) the current population and its movements.

Spain has such registers at municipality level, the Padrónes municipales (Municipal Population Registers). These population registers record individuals by recording their nationality, place of birth, age, or marital status. Since the law of 10 January 1996, the Padrón has been updated annually with the National Statistical Institute (INE) being responsible for quality control. The INE makes this data available under the name Padrón Continuo (continuous register). The Spanish register has several advantages, which make it a source of choice for work on migratory phenomena, especially those regarding foreign nationals. First, registration on the registers is compulsory and opens access to public health and education systems. On the other hand, registration of illegal immigrants is permitted, reducing the known under-registration bias due to the administrative situation. ${ }^{2}$

These reasons explain why most migration studies in Spain use data specifically produced by INE, the Residential Variation Statistics (Estadistica de Variaciones Residenciales, EVR), based on the Padrón but concerned with residential migration flows. The study by Martí and Ródenas (2012) highlights the high quality of the EVR and its superiority over other migration surveys. Though the EVR provides information about flows between municipalities, it does not provide longitudinal information that would allow migrants to be tracked. Therefore, it cannot be known whether an immigrant from a municipality is the emigrant of a previous year. Since there is no longitudinal information available, the EVR is of less interest for our study. For this reason, we chose the Padrón Continuo which provides information in terms of stocks of foreign population, allowing a diachronic view of these stocks. This source of data makes it possible to insist on the existence or impermanence in the localization of certain groups.

Though the Spanish population registers are a preferred source for studying spatial distribution, we must nevertheless mention their limits. First, registers may sometimes overestimate the number of foreigners who leave Spain without being removed from the register (or when a community delays in removing individuals from the register). In recognition of this limit, the INE implemented two sets of measures in 2004 and 2006 to automatically remove foreign nationals from the register when they do not renew their registration every 2 years. Padrón's second limitation is related to categorization; the acquisition of Spanish nationality (or dual nationality) by a number of foreign (especially Latin American) immigrants has led to the disappearance of individuals as foreign nationals, although they remain immigrants. Moreover, referring to places of birth instead of nationality would not be a solution. Using this criterion, Spaniards born outside the national territory would be considered as foreign nationals. ${ }^{3}$ Such cases have been numerous since the emigration of the Franco period. 
Municipal registers are therefore a source of choice, on which sufficient reliance can be placed to map the spatial distribution of foreign nationals in detail at the level of the Spanish municipalities, i.e. more than 8000 territorial units. In view of the large number of nationalities considered by population registers, ${ }^{4}$ we chose to limit ourselves to the most represented nationalities according to their presence on the territory (Table $1^{5}$ ). We, first of all, distinguish foreign nationals from the European Union, with special attention paid to Romanians, the most present nationality in Spain in terms of numbers, but also to the British and Germans. All the African nationals are grouped in the same category, but the Moroccans will still be studied separately, since they constitute the second largest national group after the Romanians. The Chinese have constituted a weighty presence in Spain over the last 10 years and will also be observed. Finally, we will also focus on Latin American nationals, taken as a whole and observed separately covering five countries (Argentina, Bolivia, Colombia, Ecuador, Peru).

\section{Data processing: the need for data aggregation}

To address the mapping of foreign nationals in Spain, we have compiled data from the Padrónes municipales on the INE website (http://www.ine.es/) from 1996 to 2013. Maps are based on the global administrative area database (https://gadm.org/), transformed by the authors to be consistent with INE data. From the analysis of this period, only the years 1998, 2008, and 2013 are presented here. Established in 1996, it took 2 years for the Spanish population registers to become reliable. The year 1998 therefore constitutes the year of reference for our work. ${ }^{6}$ Moreover, the development of migration and the presence rate of foreign nationals steadily increased until 2008, which makes this year a remarkable milestone. The economic crisis gripped Spain from 2009 onwards. Significant changes have taken place over several years and continue to this day (Mas Giralt, 2017). Thus, 2013 appears to be an interesting date, since this is the first year in which the Spanish population decreased since the middle of the nineteenth century. ${ }^{7}$

Like most of the world's municipal divisions, the Spanish municipal network has experienced changes over time. The law of 10 January 1996, which provides for inspection of the registers, also requires that this division be reviewed every year, in particular due to growing urban sprawl (Hallu, 2005). We have therefore aligned the data for the various years starting from 2013 to obtain the same number of municipalities for the three study dates.

\begin{tabular}{|c|c|c|c|c|c|c|c|}
\hline & Germans & $\begin{array}{l}\text { British } \\
\text { nationals }\end{array}$ & Bulgarians & Romanians & Moroccans & $\begin{array}{l}\text { All African } \\
\text { nationals }\end{array}$ & Chinese \\
\hline 1998 & 59,673 & 74,766 & 1453 & 2258 & 11,043 & 146,891 & 11,611 \\
\hline 2008 & 181,173 & 352,956 & 153,973 & 731,802 & 652,695 & 909,753 & 125,914 \\
\hline \multirow[t]{2}{*}{2013} & 181,898 & 385,178 & 168,997 & 870,256 & 792,157 & $1,103,529$ & 181,700 \\
\hline & Argentinians & Bolivians & Peruvians & Colombians & Ecuadorians & $\begin{array}{l}\text { All Latin } \\
\text { Americans }\end{array}$ & $\begin{array}{l}\text { Total } \\
\text { foreigners }\end{array}$ \\
\hline 1998 & 19,135 & 1249 & 19,757 & 9997 & 3972 & 131,215 & 637,085 \\
\hline 2008 & 147,382 & 242,496 & 121,930 & 284,578 & 427,718 & $1,784,879$ & $5,268,762$ \\
\hline 2013 & 98,351 & 173,702 & 110,150 & 222,540 & 263,498 & $1,452,770$ & $5,546,238$ \\
\hline
\end{tabular}


Once this work was completed, a first mapping revealed a strong heterogeneity in terms of the surface area of the communes. This heterogeneity has direct consequences on the variance of the population size and induces loud statistical repercussions when we attempt to measure rates. Map 1 shows the existence of a broad crescent running from the east to the west of Madrid, passing through the north, composed of small municipalities where very few inhabitants reside. Mapping at a municipal level, of course, offers a significant improvement compared to the level of the 50 provinces usually found in scientific literature. Nevertheless, the extreme heterogeneity induced by the variation of the size of the municipalities, as well as the statistical repercussions produced by the effect of the small numbers on the variability of the calculated rates, led us to envisage an aggregation of the municipal data. As Arbia wrote: "Everything is related to everything else, but things observed at a coarse spatial resolution are more related than things observed at a finer resolution" (Arbia, Benedetti, and Espa, 1996), meaning that spatial autocorrelation may be weaker for smaller administrative units (see also an empirical experiment in (Oliveau, Doignon, and Guilmoto, 2013). However, there is no intermediate administrative level between the municipalities and the provinces that would allow us to change our level of analysis, as is possible in several other Mediterranean countries (Doignon and Oliveau, 2015).

We therefore opted for an aggregation based on geographical criteria, emulating the method Guilmoto and Oliveau (2007) used to make China and India geographically and demographically comparable. The municipal network is reduced to a series of centroids which are then aggregated according to regular spacing. The result is a reduction from 8107 to 2972 points, which can then be transformed into Thiessen polygons to cover the entire territory. We shall name them municipal clusters. This transformation considerably reduces variability in the surface areas of the geographical spaces under study. Thus, the variation coefficient of the area increases from 1.4 for the municipalities to 0.4 for the clusters, and the same for the population (see Table 2 for the descriptive statistics of these two levels).

The proposed mapping of foreign nationals becomes much more readable (Map 2). With a more regular grid system, the measures we go on to propose, including in terms of spatial autocorrelation, ${ }^{8}$ will be less biased. Regular frames tend to globally homogenize the number of neighbours of each unit and to reduce edge effects (Reynolds, 1998).

\section{Methodology and results: clustering and isolation of nationalities}

To analyze the spatial distribution of the different groups of foreign nationals on Spanish territory, we have articulated two proven methods of spatial analysis. The first is based on global spatial autocorrelation measures that are locally disaggregated, the LISA developed by Luc Anselin (1995). The second method consists of mapping the results of a HAC referring to the proportion of each nationality in the population (in \%).

Table 2 Descriptive statistics of municipalities and clusters

\begin{tabular}{llll}
\hline & $\begin{array}{l}\text { Number of } \\
\text { entities }\end{array}$ & $\begin{array}{l}\text { Average surface } \\
\text { area }\end{array}$ & $\begin{array}{l}\text { Variation coefficient of the surface } \\
\text { area }\end{array}$ \\
\hline $\begin{array}{l}\text { Municipalities } \\
\text { Aggregates of }\end{array}$ & 8107 & 62.35 & 1.48 \\
municipalities & 2972 & 92.81 & 0.39 \\
\hline
\end{tabular}




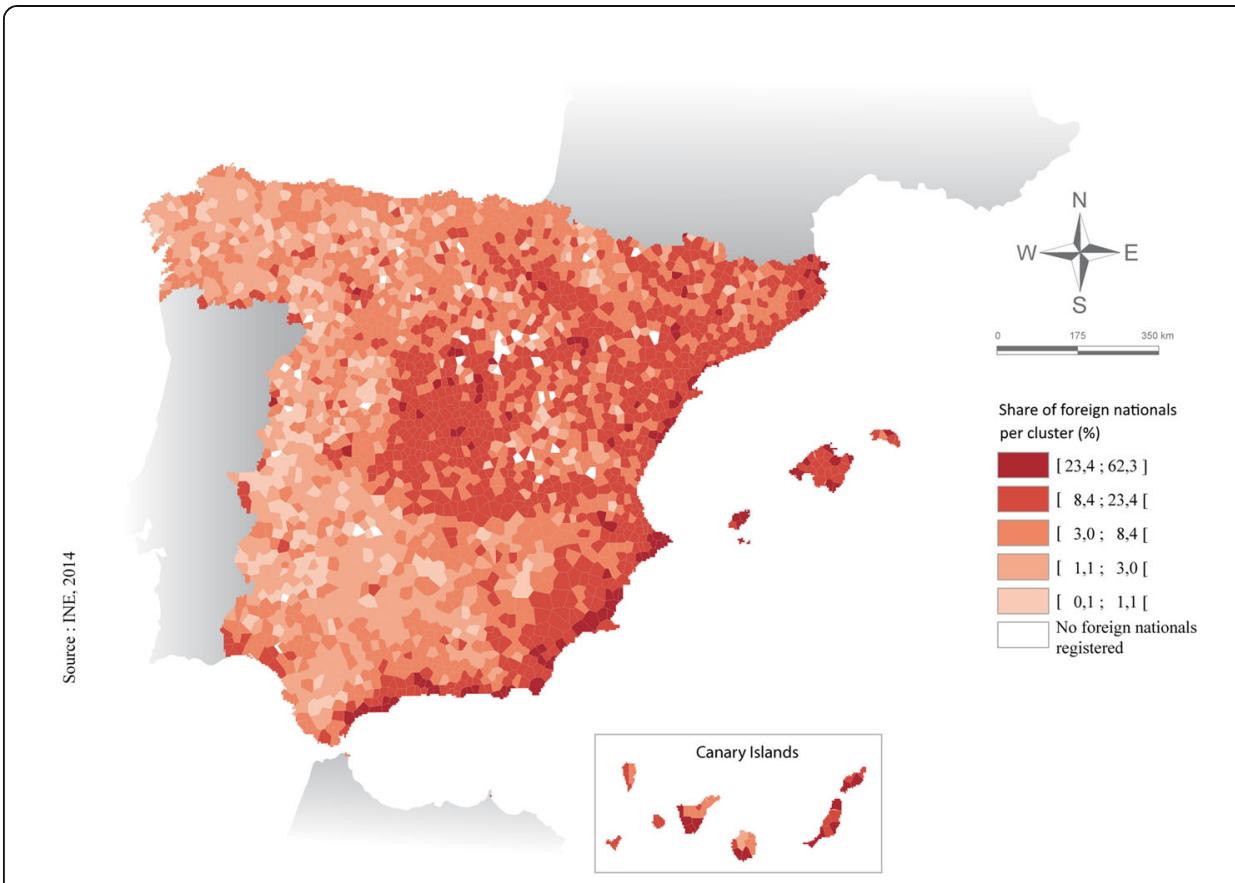

Map 2 Percentage of foreign nationals in Spain in municipal clusters (source: Continuous Register, INE)

\section{Clustering dimension}

The spatial autocorrelation measure provides information on the level of spatial structuring of an indicator, i.e. the "clustering" dimension of Reardon and O'Sullivan (2004). It can be very useful to describe the spatial registration of a demographic phenomenon (Oliveau and Guilmoto, 2005). There are many indices for measuring spatial autocorrelation, but currently the most widespread is Moran's $I^{9}{ }^{9}$

Originally developed by Moran (1950), Cliff proposed a generalized form of the Index that allowed its dissemination and popularization (Cliff and Ord, 1981).

Moran's $I: \frac{n}{m} \times \frac{\sum_{i} \sum_{j} w_{i j}\left(z_{i}-\bar{z}\right)}{\sum_{i}\left(z_{i}-\bar{z}\right)^{2}}$.

We used row standardization of the weighting matrix, which allowed us to simplify its formula and develop the LISA as follows:

Moran's $I$ after row standardization of the weighting matrix: $\frac{\sum_{i} \sum_{j} w_{i j}\left(z_{i}-\bar{z}\right)\left(z_{i j}-\bar{z}\right)}{\sum_{i}\left(z_{i}-\bar{z}\right)^{2}}$.

Hence, LISA of Moran's $I$ is $\frac{\sum_{j} w_{i j}\left(z_{i}-\bar{z}\right)\left(z_{j}-\bar{z}\right)}{\sum_{i}\left(z_{i}-\bar{z}\right)^{2}}$

We are in a world of spatial statistics. The letters " $x$ " and " $y$ " are therefore reserved for statistical unit coordinates.

$i$ : statistical unit

$z_{\mathrm{i}}$ : value of the variable for the unit $i$ and the average $\bar{z}$

$j$ : neighbours of the unit $i$

$n$ : total number of units in the sample

$m$ : total number of pairs of neighbours 
$w_{i j}$ : weighting matrix (in this case the contiguity matrix), where elements take, for example, the value " 1 " for the $i, j$ neighbours and " 0 " otherwise.

In addition to its greater statistical robustness, its variation between -1 and +1 going through 0 makes it similar to a linear correlation coefficient and justifies its popularity. When the index tends towards 1 , it indicates that the neighbouring territories tend to resemble one another. When the index tends to -1 , the neighbouring territories have opposing values. Finally, when the index approaches 0 , there is neither resemblance nor opposition between neighbours. The Moran index remains a global measure. It gives an indication of the general tendency of all the territories to be grouped or not. Like any global measure, it remains blind to the possible presence of local spatial autocorrelation phenomena. This is why other indices have been developed to overcome this lack of global measures, the LISA (Anselin, 1995), and $G^{10}$ and $G^{*}$ statistics (Getis and Ord, 1992).

We will use LISAs here, which are directly related to Moran's $I$ and have been widely used for more than a decade. Calculations were made with Geoda 1.8 (https://geodacenter.github.io/), using a first-order ${ }^{11}$ queen contiguity matrix; ${ }^{12}$ 99,999 permutations were made for each calculus. These allow identification of the spatial entities that participate most in the global spatial autocorrelation. LISAs provide information on the level of resemblance of each unit to his or her neighbours. We can also measure the extent of this resemblance. The result is a categorization of the territories into five types according to the value taken by the variable studied. We first find the territories where values are strong and whose neighbours also have strong values (positive spatial autocorrelation). These groupings are called "hot spots" and are shown in red. The second category includes territories where values are low and where neighbourhood is also characterized by low values (positive spatial autocorrelation), which are called "cold spots" since they are opposite to "hot spots". They are shown in navy blue. Then come the units whose values are opposite to those of their neighbours, called "outliers" and shown in pink when they have a strong value in an environment of weak values or in light blue when they have a low value in an environment of strong values. Local territorial associations that do not differ significantly from average values constitute the last type, shown in white. This typology makes it possible to produce a fine mapping of the spatial autocorrelation for the analyzed variable (see the set of maps below).

First, the measure of the overall spatial autocorrelation of the proportions of the main nationalities in the population (in \%) present in Spain shows very different spatial structuring levels (Table 3). The study of the Moran's I reveals that most

Table 3 Global Moran index for selected nationalities in Spain

\begin{tabular}{llllllll}
\hline & Germans & British nationals & Bulgarians & Romanians & Moroccans & All African nationals & Chinese \\
1998 & 0.335 & 0.326 & - & - & - & 0.332 & - \\
2008 & 0.560 & 0.487 & 0.420 & 0.489 & 0.399 & 0.419 & 0.234 \\
2013 & 0.570 & 0.482 & 0.407 & 0.495 & 0.397 & 0.420 & 0.323 \\
& Argentinians & Bolivians & Peruvians & Colombians & Ecuadorians & All Latin American & \\
1998 & N/A & - & - & - & - & 0.307 \\
2008 & 0.372 & 0.215 & 0.212 & 0.227 & 0.396 & 0.438 \\
2013 & 0.303 & 0.177 & 0.156 & 0.190 & 0.405 & 0.434 \\
\hline
\end{tabular}


nationalities present a non-random spatial distribution, since their index exceeds 0.2 (all the results are highly significant with $p$ value $<0.00001$ ). This is particularly the case for non-Spanish-speaking populations. Only Bolivians, Peruvians, and Colombians have a Moran's $I$ lower than 0.3. In the same way, the general trend is to accentuate the spatial structures specific to each nationality between 1998 and 2008, since the Moran's $I$ increased for all nationalities. The economic crisis from 2009 slowed down this trend if not interrupting it. The level of spatial structuring has been stabilizing for the Germans, the British, the Romanians, the Moroccans, the Africans, the Ecuadorians, and the Latin Americans. Conversely, Bulgarians and the majority of Latin American nationalities (Argentinians, Bolivians, Peruvians, Colombians) have a weakening spatial structure (a decreasing Moran's $I$ ). Only the Chinese have significantly increased their spatial structure between 2008 and 2013, with a Moran's $I$ that increased from 0.23 to 0.32 . This phenomenon can be explained by the large influx of citizens of this nationality, which led to reinforcing the structure of their location.

LISA mapping revealed distributions and spatial concentrations specific to each nationality. We chose not to comprehensively represent the maps of all the nationalities, but to make a selection of the most telling ${ }^{13}$ for the year 2013: the Germans, the British, the Romanians, the Bulgarians, the Latin Americans, the Moroccans, and the Chinese.

With the highest Moran's I, the Germans constituted the most spatially clustered nationality. A LISA map of the proportion of foreigners of German nationality in Spain (Map 3) shows their regrouping represented in red, very strong on the Mediterranean coasts (mainly near Alicante, Murcia, and Malaga) as well as in the Canary Islands and Balearic Islands. Conversely, blue zones are "cold spots" marked by the weak presence of Germans.

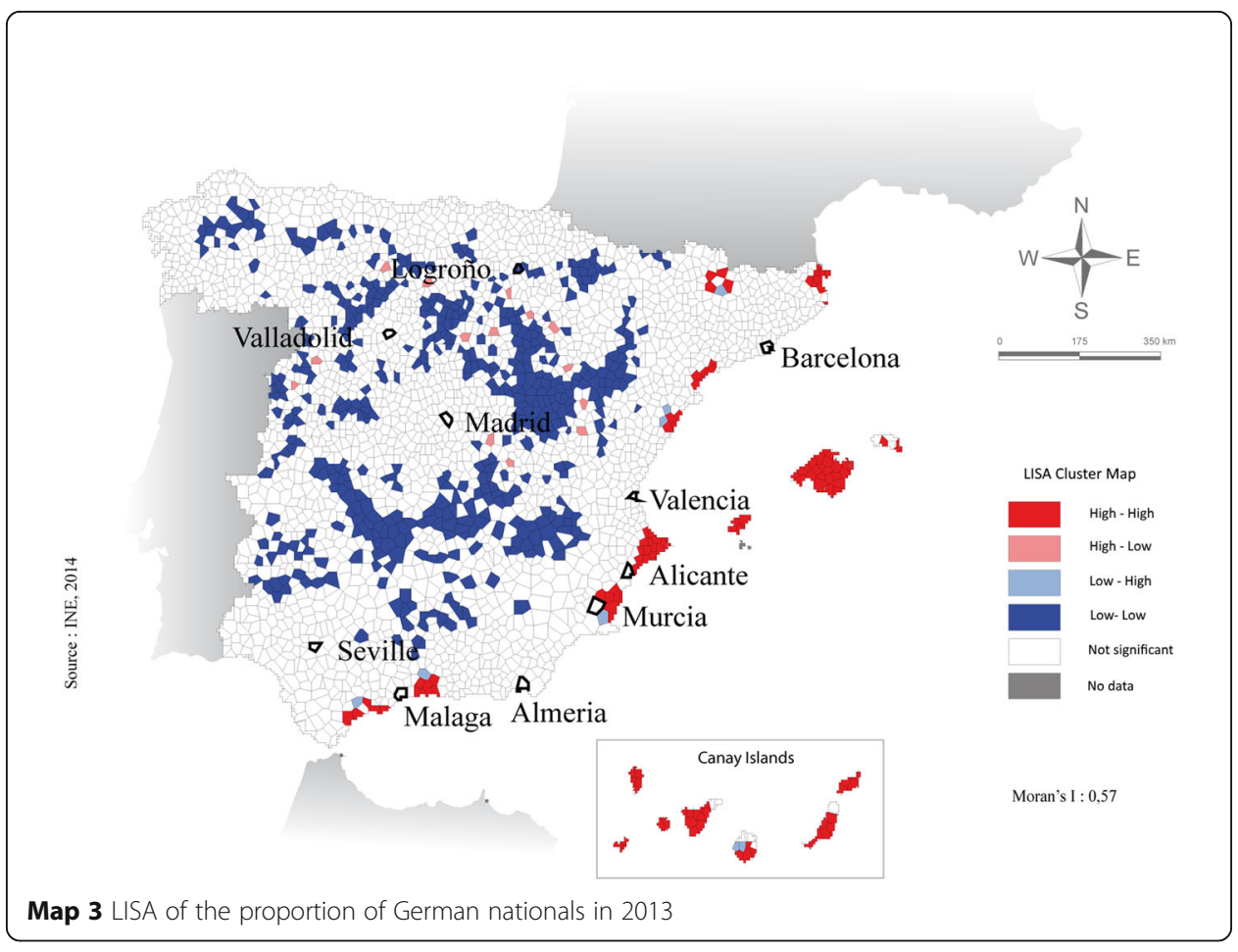


The British, far more numerous than the Germans, were present in similar spaces, but were less concentrated, since the overall index was lower and the hot spots more extensive (Map 4). The British were also concentrated mainly in the vicinity of the large agglomerations (Alicante, Murcia, Almería, Malaga) on the southern Mediterranean coastline, but spread further inland than the Germans.

The Romanians formed the most numerous foreign minority and had a very characteristic spatial distribution (Map 5). They were located in the outlying rural areas of the capital, in the coastal area between around Castellón de la Plana, where they migrated since the 1990s as unskilled workers (Bernat and Viruela, 2011). They were also very present in the urban areas of Lleida and Saragossa but were absent from the islands. In these areas, they often represented the only foreign minority, or at least the dominant minority in terms of numbers.

Bulgarians occupied mainly rural areas along a diagonal running from the north-west of Valladolid and descending towards Alicante (Map 6). In this diagonal were found pockets of concentration, which were characterized by a monopoly of occupation by the Bulgarians or sometimes sharing with the Romanians.

Moroccans formed the second foreign minority in Spain behind the Romanians (Map 7). Their spatial distribution follows three complementary factors. On the one hand, they occupied the coastal rural spaces from Malaga to the French border. On the other hand, they occupied inland rural spaces which were not occupied by Romanians or Bulgarians (complementary factor). Finally, Moroccans were found in the spaces occupied by the Germans and the British (littoral cities and islands). Romanian, Bulgarian, and Moroccan citizens often specialize in specific economic sectors: the agricultural sector for the first, the industrial sector for the second, ${ }^{14}$ and the construction, tourism, and agriculture sectors for the last.

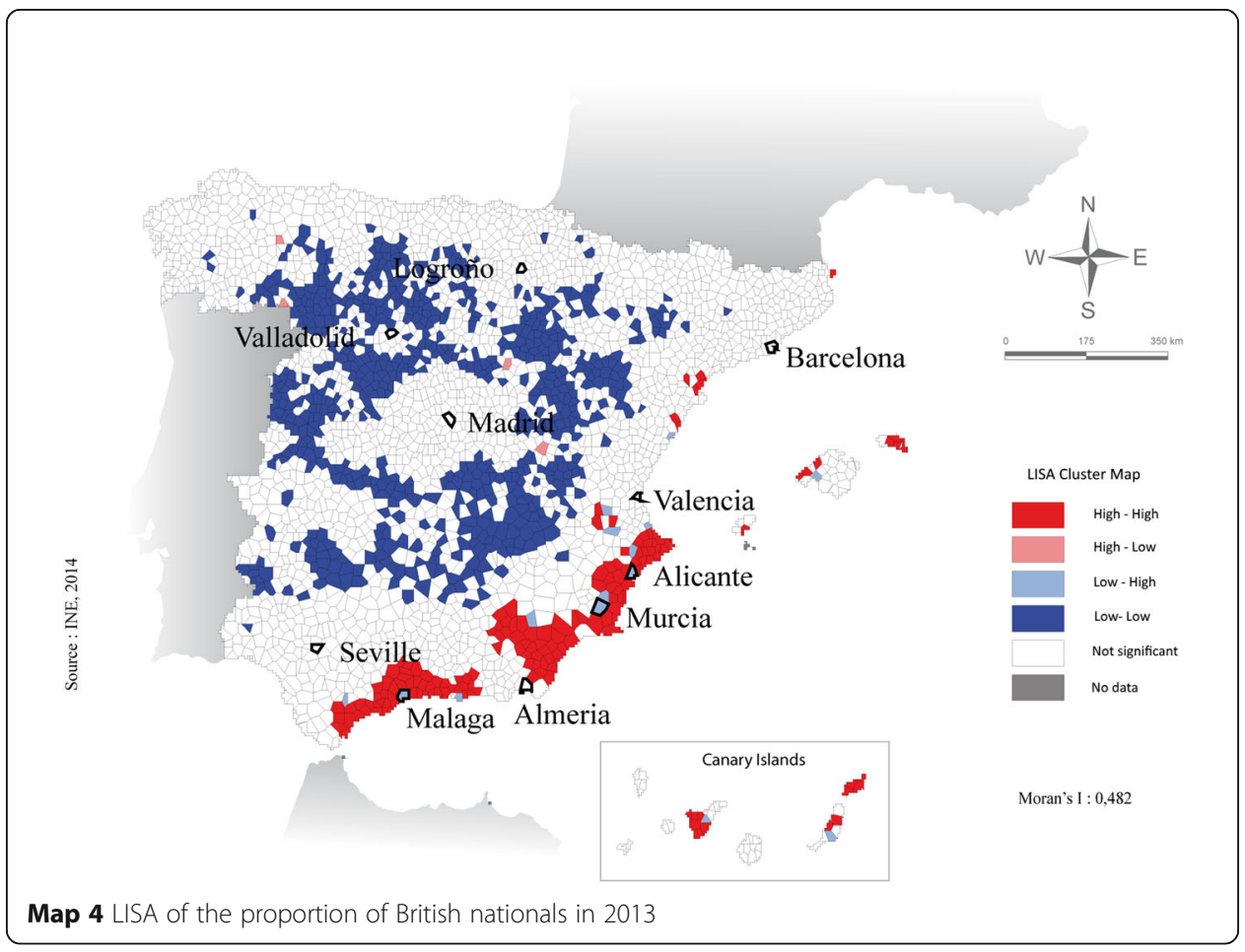




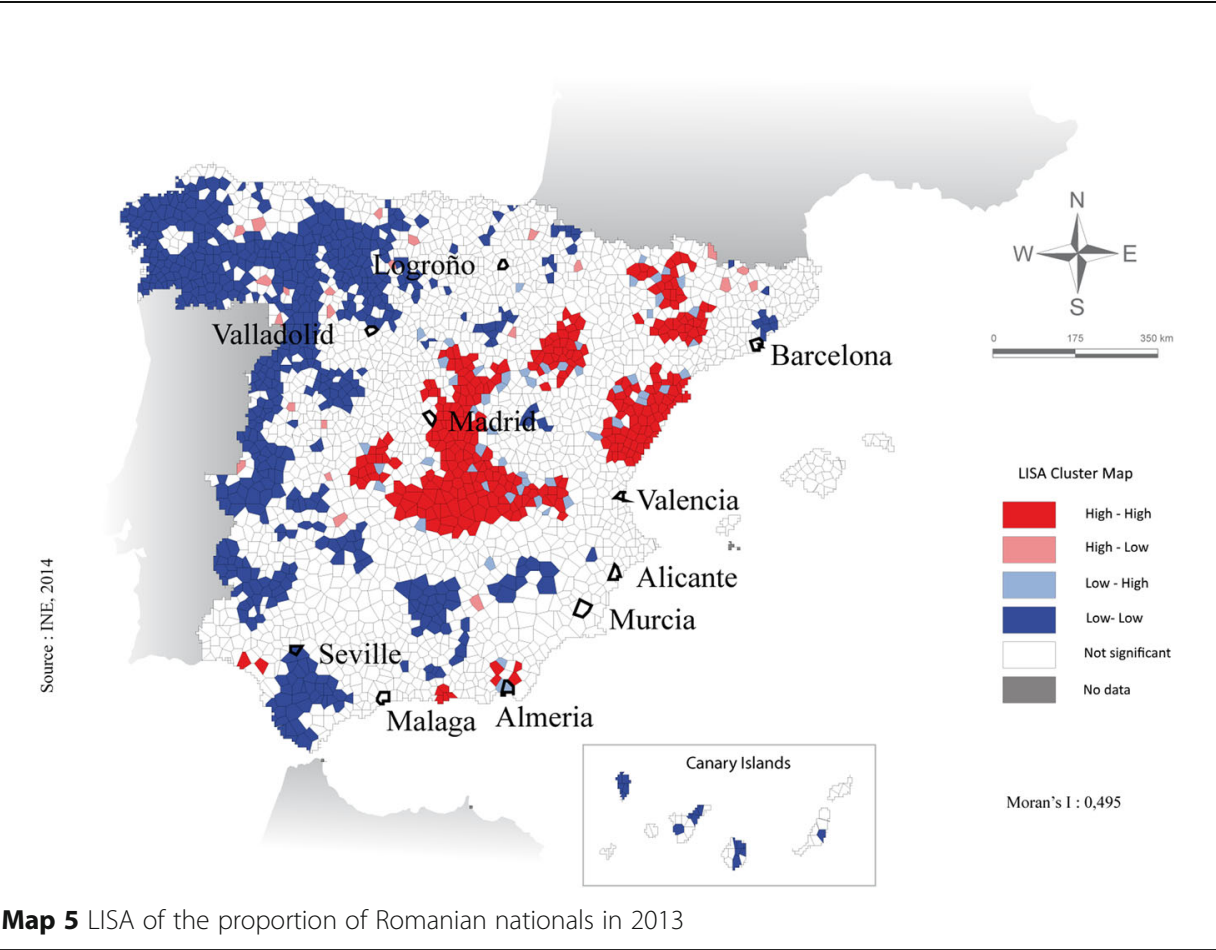

Different Latin American nationalities often exhibit comparatively similar settlements. We have therefore chosen to group them for our analyses (Map 8). Citizens of South American countries were mainly grouped in the major urban centres (Madrid, Barcelona, Murcia, Alicante, Saragossa, Girona, etc.) as well as in the islands. Their presence in Spain is largely explained

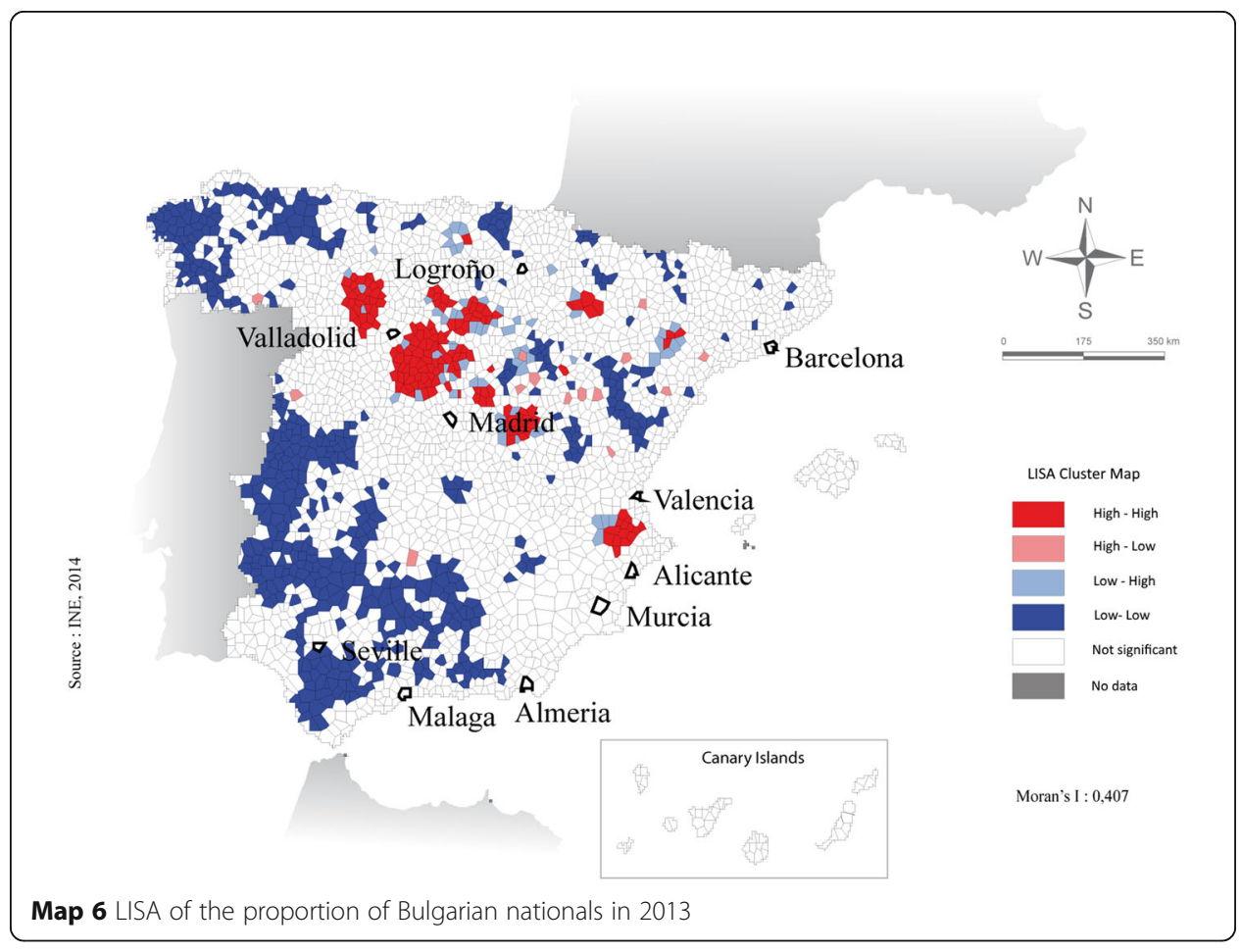




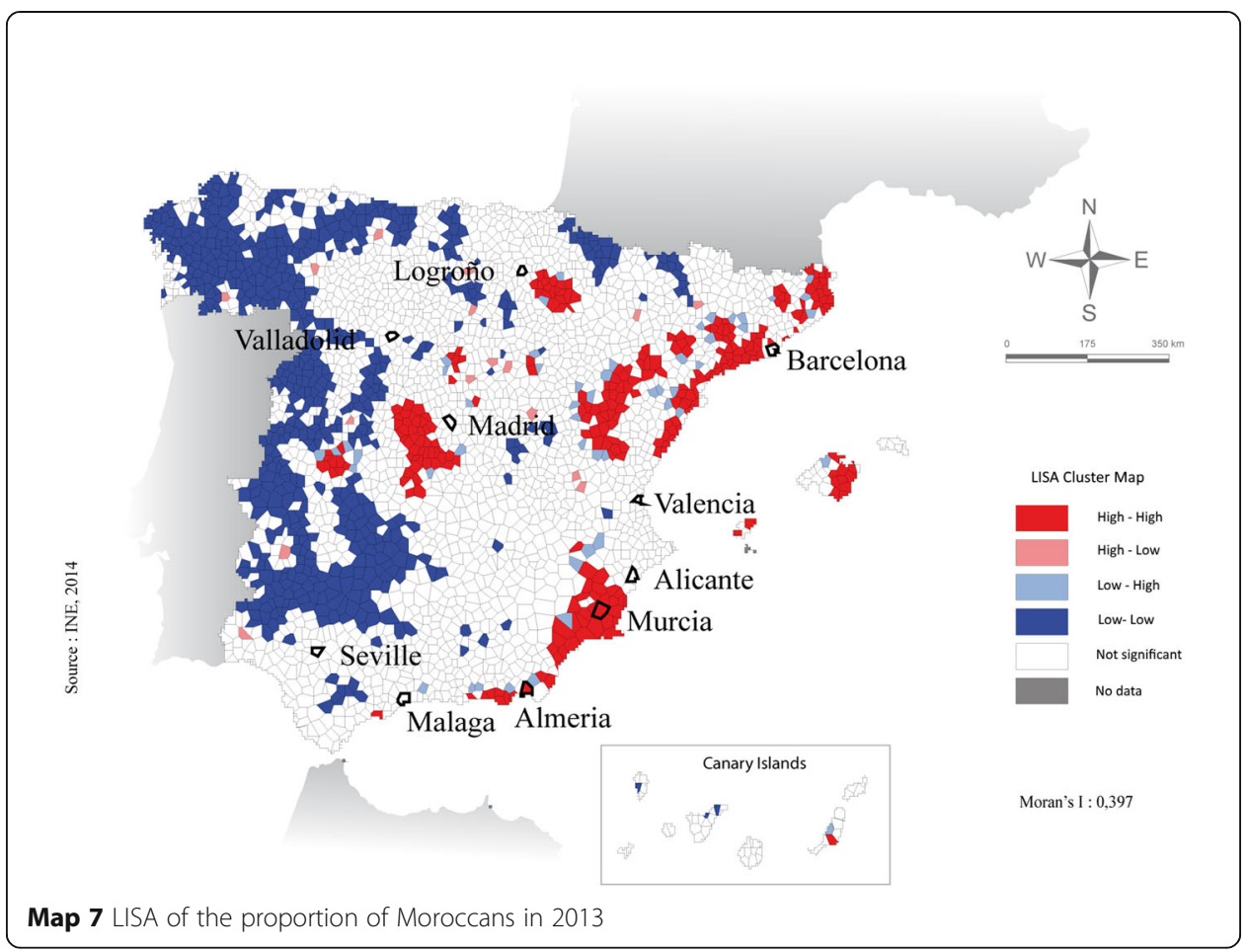

The Chinese constituted the last group studied. Having arrived in Spain more recently, the Chinese constituted an increasing minority. They were primarily located in the urban centres (Madrid, Murcia, Alicante, Valencia, Barcelona) and the islands (Map 9). The low number of cold spots on the map are worthy of note, testifying to broad dispersion across the territory, and is the result of smaller numbers,

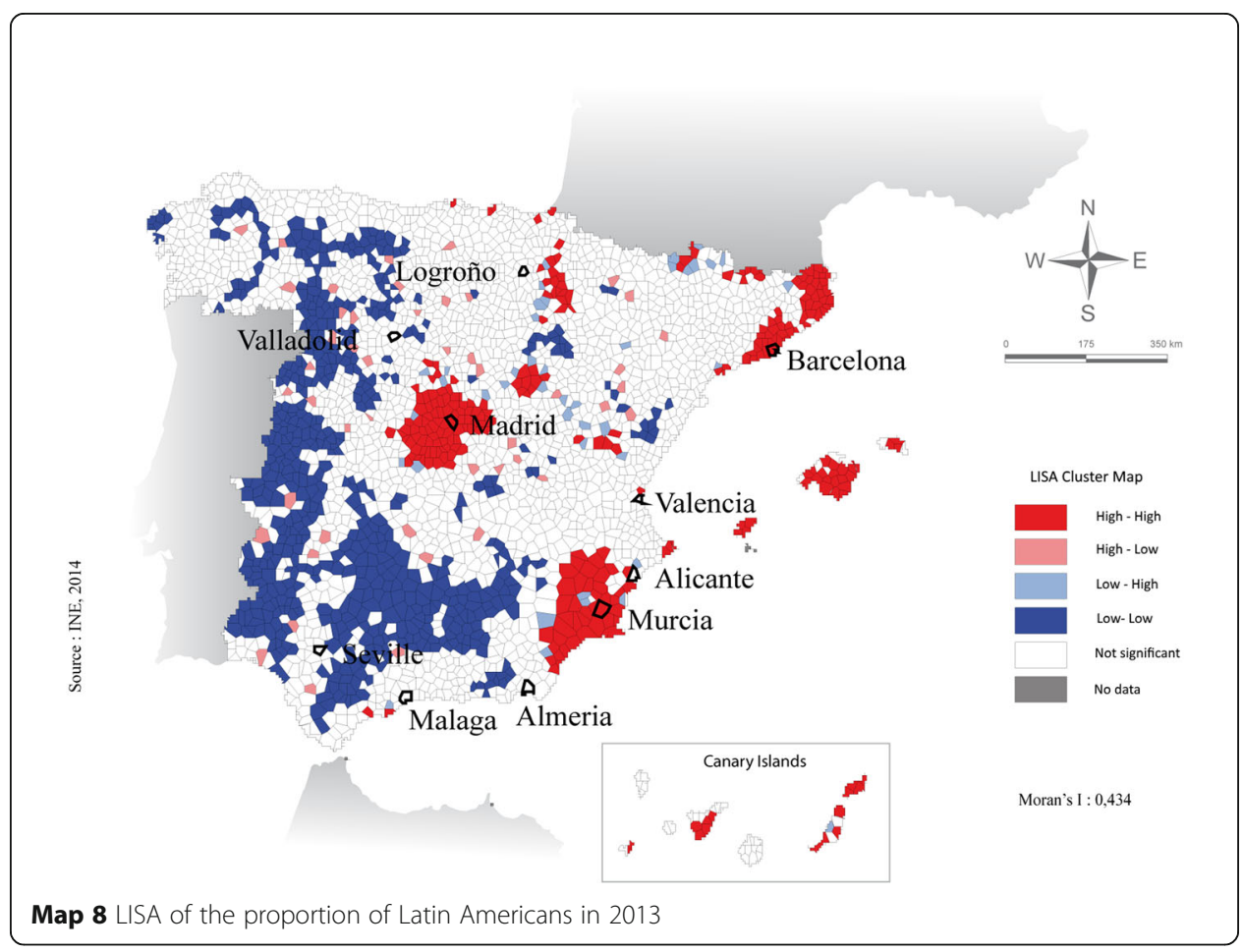




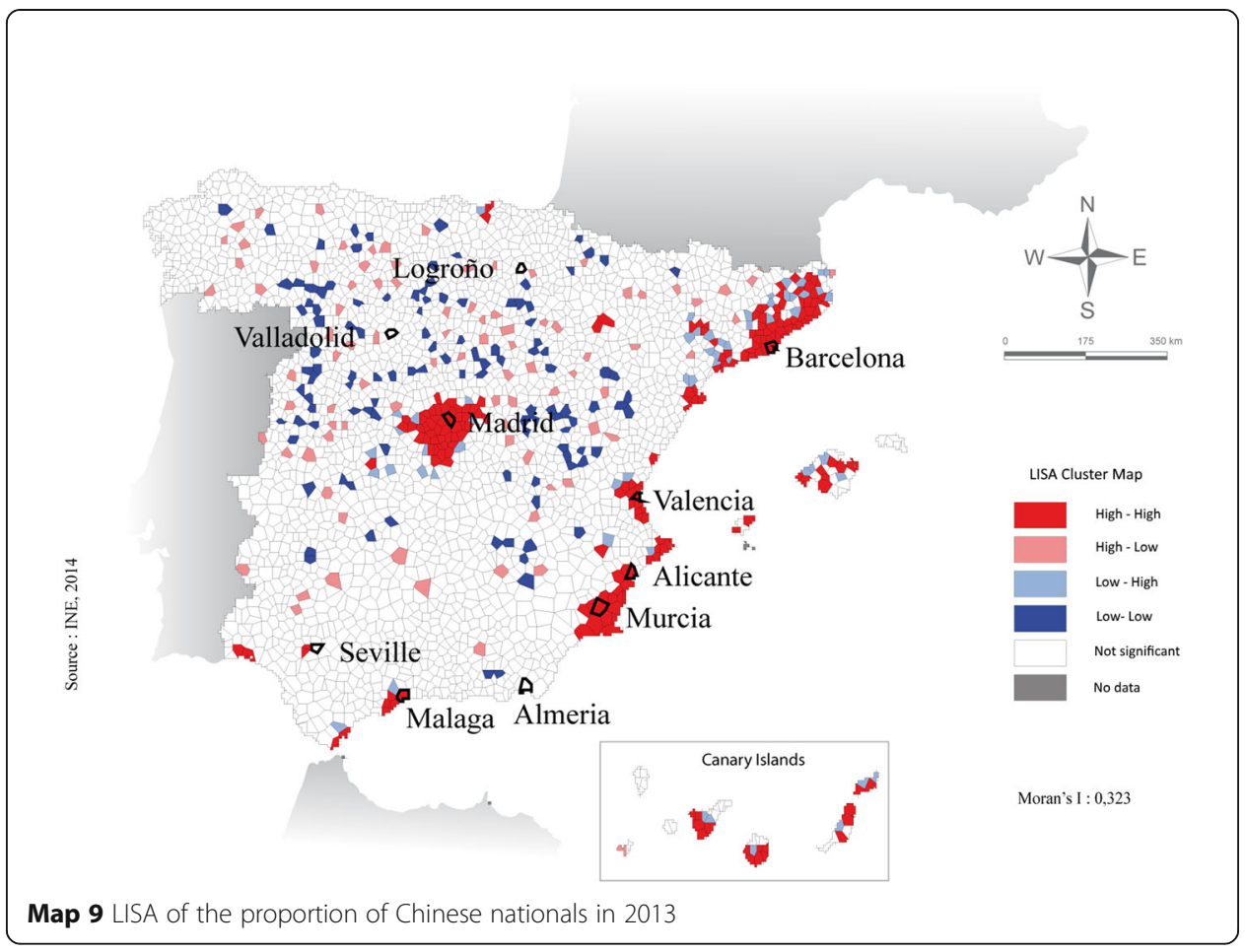

resulting in fewer population contrasts. LISAs therefore have more difficulty detecting concentrations.

The first results of the analysis of clustering dimension of nationalities confirm what the literature says about the migrant's patterns. It shows clearly the strong clustering of each nationality in Spain. It also underlines the specificities of each nationality, with concentrations which vary across space.

\section{Isolation dimension}

LISA mapping enables the traditional reading of statistical maps to go even further, to propose an interpretation of the phenomena that is already regional. We wished to supplement it with a multivariate analysis which makes it possible to better showcase the various groupings of nationalities (the "isolation" dimension of Reardon and O'Sullivan (2004)). For this purpose, we relied on an HAC of the rates of foreign nationals of each nationality in each municipal cluster. The result is an eloquent classification.

The HAC highlights the deviations from the average distribution. In an HAC, the statistical units (here, the municipal clusters) are grouped according to their similarity. Each class brings together a group of units whose characteristics are comparable and which deviate from those of the characteristics of other classes. A standard profile can be drawn for each class, which indicates the average value of the class and compares it to the average of the entire population. The profiles resulting from the analysis present specific demographic situations. On Map 10, for example, the red class includes municipal clusters that show a slight overrepresentation of foreign nationals but, above all, a strong overrepresentation of German and British citizens. Conversely, there is a slight underrepresentation of Bulgarian, Romanian, and Peruvian citizens. 


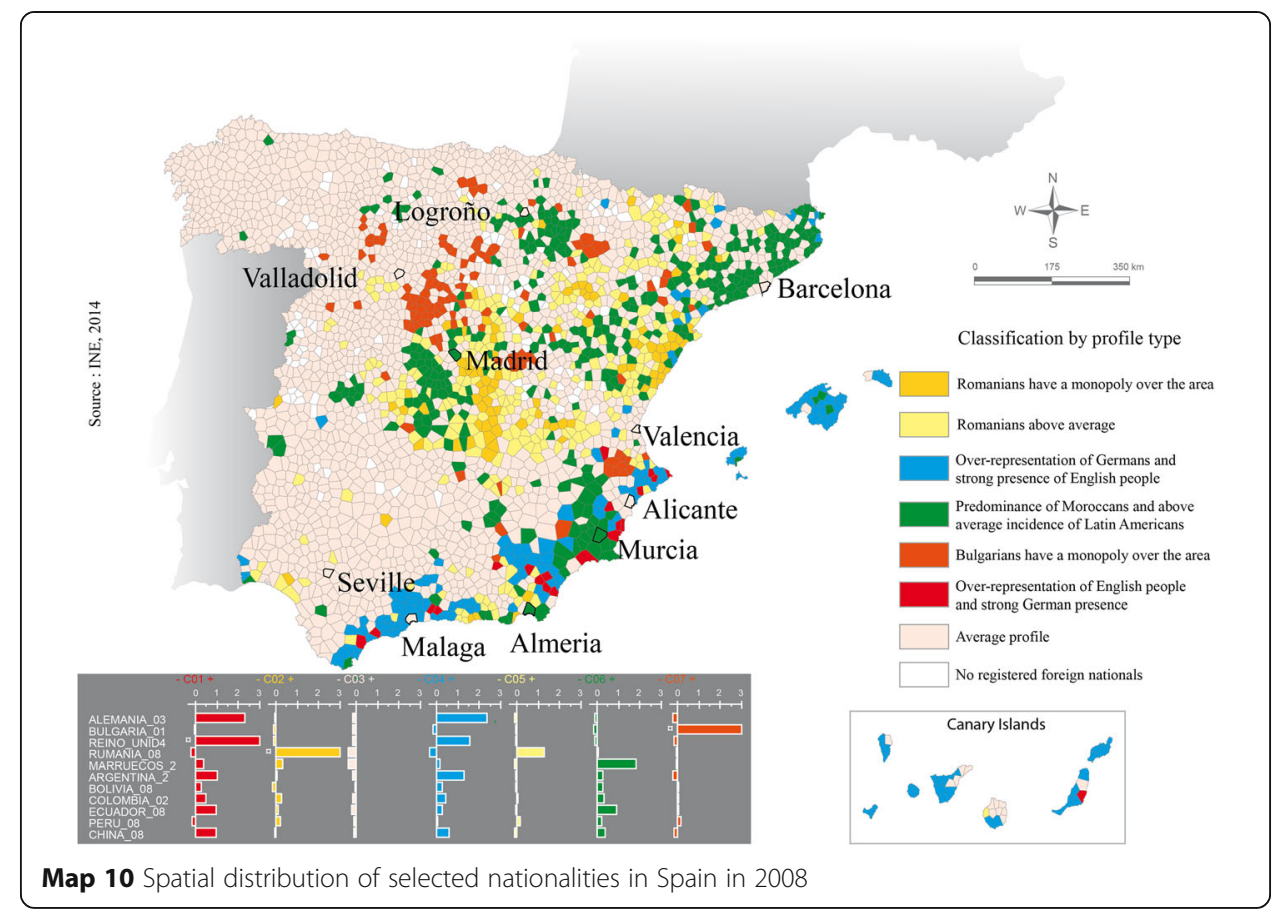

If the lack of detailed information for the year 1998 did not allow us to propose a classification (all nationalities were not presented in detail at this date), we can nevertheless map the results for 2008 (Map 10) and 2013 (Map 11). Some of the characteristics revealed in the mapping of the LISAs of each nationality are found here. Germans and Britons, although not having exactly the same spatial distribution, shared the same areas known for tourism: the Canary Islands and the Balearic Islands, south of the

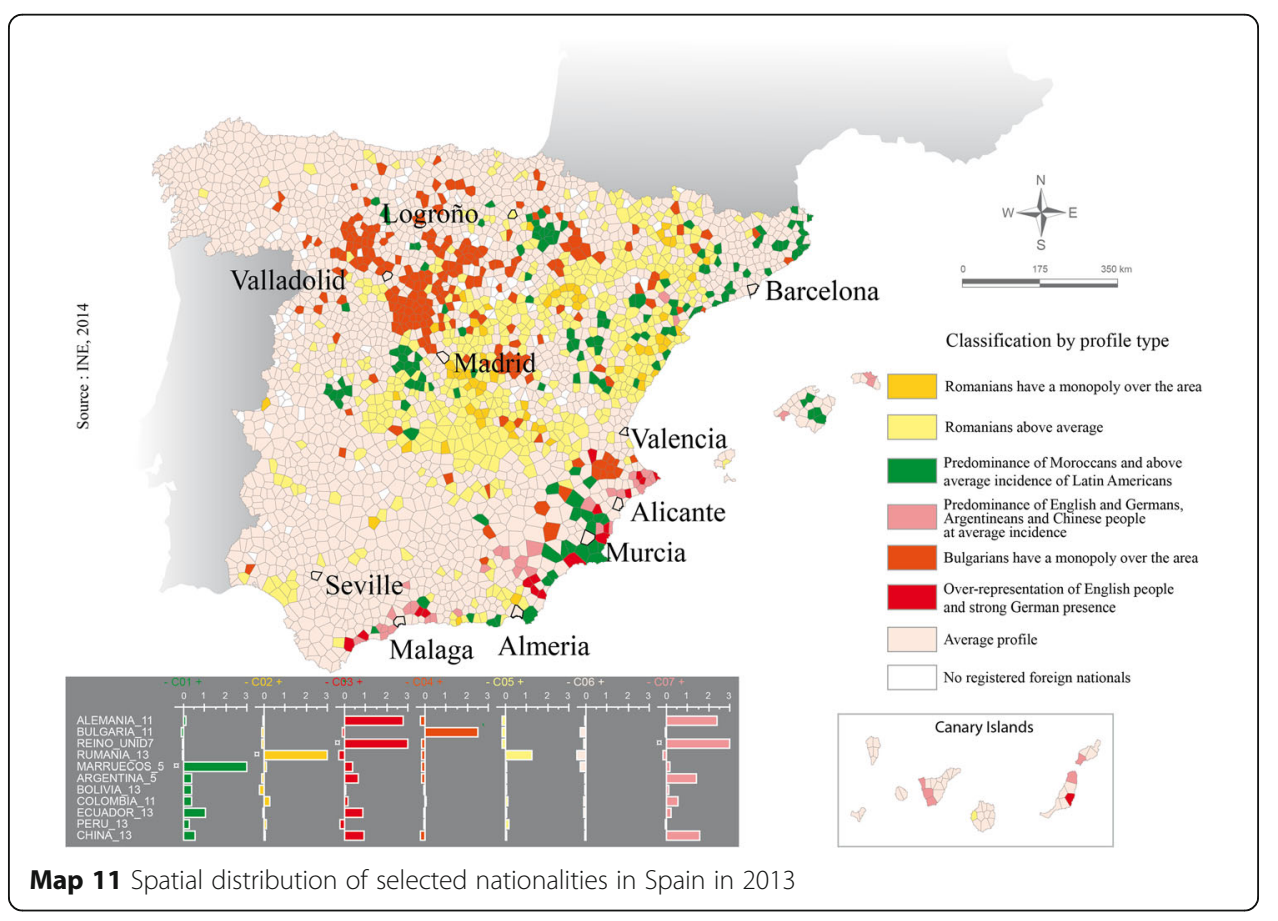


Mediterranean coast (see Pérez and Medina, 2004). Their presence was mainly linked to retirement or tourism migrations. Moroccans, Latin Americans, and Chinese also lived in these areas economically dedicated to tourism, but their role was not the same as they were working for the former. Their distribution extended well beyond, stretching up to the north and reaching the periphery of large cities. Finally, the Bulgarians and the Romanians had settled in Spanish rural areas, but differed from each other. Where the Bulgarians were present, they were practically the only foreigners. The Romanians had the same profile.

The map of the classification for the year 2013 does not have a radically different geography (Map 11). Nevertheless, it offers a rapid overview of the changes that have taken place since 2008. The areas marked in 2008 by an overrepresentation of Moroccans and Latin Americans (in green) have considerably reduced. Areas marked by an overrepresentation of foreign nationals linked to tourism have decreased. However, care must be taken not to overinterpret these changes in classification. While it is true that Latin Americans had partly left Spain to look for work further north in Europe (Mas Giralt, 2017), the classification is also sensitive to general changes in population distribution. Thus, the British have tended to be more evenly distributed throughout the territory (as evidenced by the slight decline in the Moran index in Table 2), as were foreign nationals of Latin American origin. As a result, municipal clusters that differed moderately in 2008 were no longer sufficiently distinguished in 2013 and re-enter the pink "middle profile" class.

The HAC puts forward the fact that the different nationalities do not share similarly the territory they inhabit with others. North European migrants (retired) share their recreational spaces with Moroccans and South American (workers). On the opposite, Bulgarians and Romanians tend to be alone with Spanish nationals in the region they migrated to.

\section{Toward a synthesis}

It therefore seems necessary to combine different approaches in terms of hot spots, derived from the measurement of spatial autocorrelation and LISA, with HAC. The resulting map (Map 12) superimposes the classification of the most remarkable hot spots. Confirming the undivided concentration of Bulgarians and Romanians, it underlines the diversity of cohabitation along the Mediterranean coast. The regions of Murcia and Valencia, for example, have a high concentration of Ecuadorians, which is not found as strongly elsewhere. The Germans are very concentrated in the two archipelagos (the Balearic and Canary Islands) and around some seaside towns, although the clusters do not stand out as much from the average Spanish profile.

This geography of foreign nationals in Spain is interesting in more ways than one. First, it reveals a geography whose level of detail was previously partially known on the Spanish scale. Thus, it specifically illustrates the locations of foreign nationals and subsequently draws attention to the increasingly marked dichotomy between the large cities and the Mediterranean coast, on the one hand, and the rest of the predominantly rural country, on the other hand. In addition, the country is also divided in two, with a western half marked by lower migration. More broadly, this western half has a significantly ageing demographic profile which has been demographically declining for at least 20 years (Doignon, Oliveau, and Blöss-Widmer, 2016). 


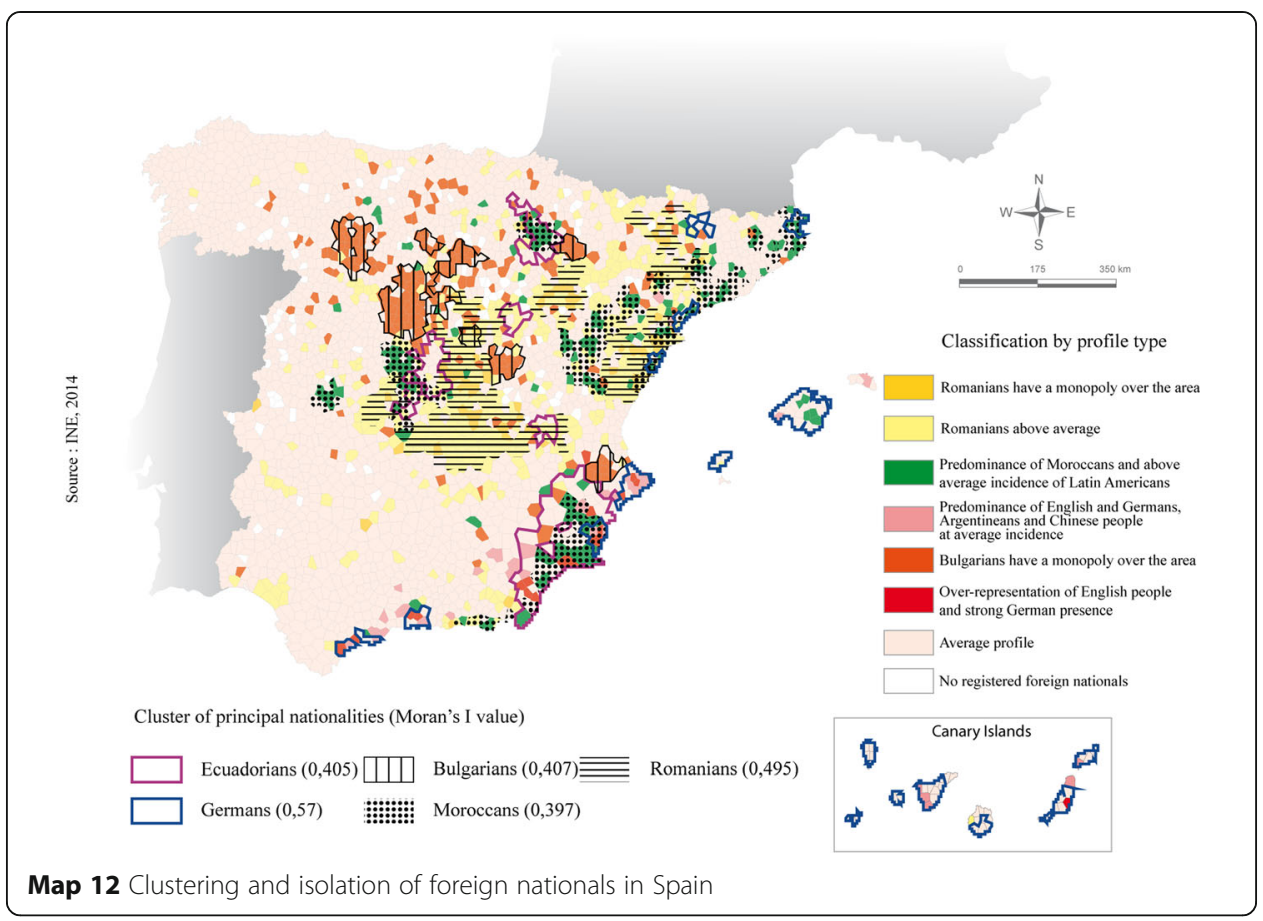

The results presented here are in accordance with those obtained by Maza et al. (2013) or Domingo et al. (2010) at the provincial level or those describing more locally the spatial distribution of migrants (Rodriguez et al., 2004; Bernat and Viruela, 2011). Over the last 15 years, Spain has undergone a huge demographic upheaval. The extremely large increase in the number of foreign nationals between 1998 and 2008 resulted in a rapid growth of the total population. The 2008 crisis has reversed this trend by reversing the migratory balance in just 2 years, resulting in a subsequent decline in the Spanish population. Spain thus appears to be a privileged field of study to describe the dynamics of migration in a Southern European country.

Population growth in the decade 2000-2010 was due to immigration (Collantes, Pinilla, Sáez, and Silvestre, 2014). Consequently, the cessation of this migration has led to a pause in this growth. Foreign nationals leave a country that can no longer offer them work. The massive departures of Latin Americans might seem surprising, since they are probably the foreigners best armed culturally and linguistically to attempt to sustainably integrate and resist economic crises. However, they are also the most qualified and the most recent arrivals. Rather than returning to their country of origin, they continued their migration route further north in Europe (Larramona, 2013; Mas Giralt, 2017).

Today, there are many questions concerning the demographic future of Spain and the related geographical prospects. Spanish fertility has maintained very low levels (less than 1.5 children per woman), largely due to the fertility of foreign women (de López and Izquierdo, 2003; Roig Vila and Martín, 2007). What would happen if the economic crisis were to continue? Once the crisis has passed, will migratory networks be able to rebuild, even though foreign nationals have settled elsewhere? In the short term, what will happen in the country's most ageing and less dynamic regions? This is as big an 
issue as the current crisis, the effects of which have been going on for 9 years now, and which remains unaddressed for the time being.

\section{Conclusion}

Access to the data of the communal population registers of each year allows a fine scale, rarely exploited, and diachronic study to be conducted. Using spatial analysis methods, including LISA measurements, we have been able to easily identify the spatial structures of foreign nationals specific to each nationality (clustering).

Thus, we have observed that Romanians, Moroccans, and Ecuadorians (who represent 1.7 million people) have strong spatial structures and are located in particular spaces. Thus, using data mining methods such as HAC, we have shown that certain nationalities are in a situation of spatial cohabitation (Moroccans and Ecuadorians in the province of Murcia) while others (the Bulgarians or the Romanians to the east of Madrid) are in a situation of spatial monopoly, or isolation in the sense of Reardon and O'sullivan.

Finally, we highlighted differentiated strategies in response to the 2008 crisis. African nationals are represented in consistent numbers after 2008, while the number of Latin Americans has been decreasing since 2009, supporting Mas Giralt's (2017) finding of a coping strategy in use by these populations. The number of EU nationals will only decrease from 2012, but moderately.

Finally, we showed that the Spanish population has decreased due to negative net migration. Is this reduction sustainable or merely cyclical? The most recent data (INE) can provide a first response. Between 2010 and 2013, net migration increased, reaching - 252,000 in 2013. Nevertheless, the haemorrhage has appeared to be declining ever since, descending to $-95,000$ in 2014 and only -2000 in 2015. The premise of economic recovery in Spain may be the cause, but we will have to wait for new data to convince ourselves of a possible new reversal of migratory flows. Moreover, the period 2010-2015 was marked by a very sharp drop in the natural balance, which became negative in 2015, raising new questions about Spain's demographic future.

\section{Endnotes}

${ }^{1}$ In the nineteenth century, the censuses took place in $1857,1860,1877,1887$, and 1897. From 1900 until 1970, then from 1981 to the present, the interval has systematically become every 10 years.

2“[...] data suggests that there were no fewer than 600,000 illegal foreign workers in mid-2011 [...]" (OECD, 2012).

${ }^{3}$ However, a foreign-born individual automatically acquires Spanish nationality if one of their parents is Spanish.

${ }^{4}$ The INEE gives details of 33 nationalities, the others being aggregated by continental groups.

${ }^{5}$ See the "Appendix" section for percentages.

${ }^{6}$ For the year 1998, INE does not provide details for all nationalities, but simply by continental groups. Therefore, the year 1998 will not be used for cartographic analyses or local spatial statistics.

${ }^{7}$ Since 1996, the INE has published Spain's official population every year on January 1. Between 2012 and 2013, the population has decreased by about 135,000 inhabitants. 
${ }^{8}$ "The literal meaning of spatial autocorrelation is self-correlation (autocorrelation) attributable to the geographic ordering of data (spatial)" (Griffith, 1993).

${ }^{9}$ The Moran's $I$ is an interpretation by Cliff (1969) of a first index proposed by Moran (1950).

${ }^{10} G=\frac{\sum i \sum j w_{i j} z_{i} z_{j}}{\sum i \sum j z_{i} z_{j}}$ The difference between $G$ and $G^{*}$ is that $G^{*}$ considers that $i$ is its own neighbor $(i=j)$.

${ }^{11}$ There is not yet any scientific way to determine a best neighbourhood. We then keep the simplest one, that is first order. Using a wider neighbourhood (i.e. bigger order) will probably decrease the level of spatial autocorrelation (Oliveau et al., 2013).

${ }^{12}$ In our case using Thiessen polygons, it makes no difference to use rook and queen contiguity.

${ }^{13}$ The maps not shown in the body of this article are available at this address: address provided after acceptance of the article to preserve the authors' anonymity.

${ }^{14}$ Thus, Bulgarian business leaders have come to settle and have developed migratory channels from their country of origin to supply labour to their companies.

\section{Appendix}

Table 4 Percentage of each group of foreign residents according to the total number of foreigners in Spain (source: Continuous Register, INE)

\begin{tabular}{llllllll}
\hline & Germans & $\begin{array}{l}\text { British } \\
\text { nationals }\end{array}$ & Bulgarians & Romanians & Moroccans & $\begin{array}{l}\text { All African } \\
\text { nationals }\end{array}$ & Chinese \\
1998 & $9.37 \%$ & $11.74 \%$ & $0.23 \%$ & $0.35 \%$ & $1.73 \%$ & $23.06 \%$ & $1.82 \%$ \\
2008 & $3.44 \%$ & $6.70 \%$ & $2.92 \%$ & $13.89 \%$ & $12.39 \%$ & $17.27 \%$ & $2.39 \%$ \\
2013 & $3.28 \%$ & $6.94 \%$ & $3.05 \%$ & $15.69 \%$ & $14.28 \%$ & $19.90 \%$ & $0.03 \%$ \\
& Argentinians & Bolivians & Peruvians & Colombians & Ecuadorians & $\begin{array}{l}\text { All Latin } \\
\text { American }\end{array}$ & $\begin{array}{c}\text { Total } \\
\text { foreigners }\end{array}$ \\
2098 & $3.00 \%$ & $0.20 \%$ & $3.10 \%$ & $1.57 \%$ & $0.62 \%$ & $20.60 \%$ & $100.00 \%$ \\
2013 & $2.80 \%$ & $4.60 \%$ & $0.23 \%$ & $5.40 \%$ & $8.12 \%$ & $33.88 \%$ & $100.00 \%$ \\
\hline
\end{tabular}

Acknowledgments

The authors are very grateful for the comments received from Elise Lévêque and Christophe Guilmoto, and for the thoroughly constructive and helpful suggestions of the anonymous reviewers.

Funding

This work is part of the SoDeMoMed project, financed by ANR Transmed (ANR-12-TMED-0005)

Availability of data and materials

All statistical data were downloaded from the INE website. Geographical data comes from GADM website.

Authors' contributions

SO wrote the article and supervised the study. QL prepared the data and conducted the analyses with YD. IB-W and

YD revised the article. All authors read and approved the final manuscript.

Competing interests

On behalf of all authors, the corresponding author declares that they have no competing interest.

\section{Publisher's Note}

Springer Nature remains neutral with regard to jurisdictional claims in published maps and institutional affiliations. 
Received: 19 November 2017 Accepted: 26 November 2018

Published online: 18 January 2019

\section{References}

Anselin, L. (1995). Local indicators of spatial association - LISA. Geographical Analysis, 27(2), 93-115. https://doi.org/10.1111/j. 1538-4632.1995.tb00338.x

Arbia, G., Benedetti, R., \& Espa, G. (1996). Effects of the MAUP on image classification. Geographical Systems, 3, $123-141$.

Bayona-i-Carrasco, J., \& Gil-Alonso, F. (2013). Is foreign immigration the solution to rural depopulation? The case of Catalonia (1996-2009). Sociologia Ruralis, 53(1), 26-51. https://doi.org/10.1111/j.1467-9523.2012.00577.x.

Bernat, J. S., \& Viruela, R. (2011). The economic crisis and immigration: Romanian citizens in the ceramic tile district of Castelló (Spain). Journal of Urban and Regional Analysis, 3(1), 45-65.

Cliff, A.D., (1969), Some measures of spatial association in areal data, Ph.D. Dissertation, University of Bristol.

Cliff, A. D., \& Ord, J. K. (1981). Spatial processes: models and applications. London: Pion.

Collantes, F., Pinilla, V., Sáez, L. A., \& Silvestre, J. (2014). Reducing depopulation in rural Spain: the impact of immigration. Population, Space and Place, 20(7), 606-621. https://doi.org/10.1002/psp.1797.

Cornelius, Wayne A. 2004. "Spain: the uneasy transition from labor exporter to labor importer". In controlling immigration: a global perspective, 2nd edition. Wayne A. Cornelius, Philip L. Martin, and James Frank Hollifield, . Stanford: Stanford University Press: 387-429.

Doignon, Y., \& Oliveau, S. (2015). Territorial grids in the Mediterranean: space versus population. Bollettino Dell'Associazione Italiana Di Cartografia, 154, 46-63.

Doignon, Y., Oliveau, S., \& Blöss-Widmer, I. (2016). L'Europe méridionale depuis 20 ans: dépeuplement, dépopulation et renouveau démographique. Espace Populations Sociétés, 2015/3-2016/1, 23. https://doi.org/10.4000/eps.6171.

Domingo, V., Domingo, A., \& Valverde, J. R. (2010). La inflexión en el ciclo migratorio internacional en España: impacto y consecuencias demográficas. In La inmigración en tiempos de crisis (pp. 182-207). Barcelona: CIDOB. https://dialnet. unirioja.es/servlet/articulo?codigo $=4207313$.

Duncan, O. D. (1957). The measurement of population distribution. Population Studies, 11(1), 27-45. https://doi.org/10.2307/ 2172508.

Getis, A., \& Ord, J. K. (1992). The analysis of spatial association by use of distance statistics. Geographical Analysis, 24(3), 189206. https://doi.org/10.1111/j.1538-4632.1992.tb00261.x.

Griffith, D. A. (1993). Spatial regression analysis on the PC: spatial statistics using SAS. In Resource publications in geography. Washington, D.C.: Association of American Geographers.

Guilmoto, C. Z., \& Oliveau, S. (2007). Sex Ratio imbalances among children at micro-level: China and India compared. New York: Population Association of America 2007 Annual Meeting http://paa2007.princeton.edu/papers/71096.

Hallu, R. (2005). Padrón et Censo, bases de la démographie en Espagne. Courrier des statistiques, 115, $19-26$.

Larramona, G. (2013). Out-migration of immigrants in Spain. Population, 68(2), 249-271. https://doi.org/10.3917/popu. 1302.0249 .

de López, L. D., \& Izquierdo, A. (2003). La huella demográfica de la población extranjera en España. Sistema: Revista de ciencias sociales, $175-176,181-200$.

Martí, M., \& Ródenas, C. (2012). Measuring international migration through sample surveys: some lessons from the Spanish case. Population, 67(3), 435-463. https://doi.org/10.3917/popu.1203.0517.

Martori, J. C., Madariaga, R., \& Oller, R. (2016). Real estate bubble and urban population density: six Spanish metropolitan areas 2001-2011. The Annals of Regional Science, 56(2), 369-392. https://doi.org/10.1007/s00168-016-0743-z.

Mas Giralt, R. (2017). Onward migration as a coping strategy? Latin Americans moving from Spain to the UK post-2008. Population, Space and Place, 23(3). https://doi.org/10.1002/psp.2017.

Massey, D. S., \& Denton, N. A. (1988). The dimensions of residential segregation. Social Forces, 67(2), 281-315. https://doi.org/ $10.2307 / 2579183$

Maza, A., Villaverde, J., \& Hierro, M. (2013). Explaining the settlement patterns of foreigners in Spain. Applied Geography, 40(juin), 11-20. https://doi.org/10.1016/j.apgeog.2013.01.004.

Moran, P. A. P. (1950). Notes on continuous stochastic phenomena. Biometrika, 37(1/2), 17-23. https://doi.org/10.2307/ 2332142.

Munoz-Pérez, F., \& Escribano, A. I. (1989). L'Espagne, pays d'immigration. Population, 44(2), 257-289. https://doi.org/10.2307/ 1533583.

OECD (2012). International Migration Outlook 2012. Paris: OCDE Publishing. https://doi.org/10.1787/migr_outlook-2012-en.

Oliveau, S., Doignon, Y., \& Guilmoto, C. Z. (2013). Neighborhood effects in demography: measuring scales and patterns. Busan: XXVIIth IUSSP International Population Conference.

Oliveau, S., \& Guilmoto, C. (2005). Spatial correlation and demography. Exploring India's demographic patterns. Tours: XXVth IUSSP International Population Conference.

Pérez, J. M. G., \& Medina, J. S. (2004). Territorio e inmigración en España. Análisis de casos en Palma de Mallorca y León. Cybergeo : European Journal of Geography, juin. https://doi.org/10.4000/cybergeo.25547.

Poulain, M., Perrin, N., \& Singleton, A. (Eds.). (2006). THESIM: towards harmonised European statistics on international migration. Louvain-la-Neuve: Presses universitaires de Louvain.

Reardon, S. F., \& O'Sullivan, D. (2004). Measures of spatial segregation. Sociological Methodology, 34(1), 121-162. https://doi. org/10.1111/j.0081-1750.2004.00150.x.

Reynolds, Harold David. 1998. "The Modifiable Area Unit Problem, Empirical Analysis by Statistical Simulation". Thesis, National Library of Canada. https://tspace.library.utoronto.ca/handle/1807/12105.

Rodriguez, V., Fernandez-Mayoralas, G., \& Rojo, F. (2004). International retirement migration: retired Europeans living on the Costa del Sol, Spain. Population Review, 43(1), 1-36. https://doi.org/10.1353/prv.2004.0009.

Roig Vila, M., \& Martín, T. C. (2007). Childbearing patterns of foreign women in a new immigration country. Population, 62(3), 351-379. https://doi.org/10.3917/popu.703.0419. 